\title{
Frontières
}

Légaré, Jocelyne (dir.), Jamais de la vie. Écrits et images sur les pertes et les deuils, Montréal, Les éditions du passage, 2001, $190 \mathrm{p}$.

\section{Diane Laflamme}

Volume 14, numéro 2, printemps 2002

URI : https://id.erudit.org/iderudit/1073983ar

DOI : https://doi.org/10.7202/1073983ar

Aller au sommaire du numéro

Éditeur(s)

Université du Québec à Montréal

ISSN

1180-3479 (imprimé)

1916-0976 (numérique)

Découvrir la revue

Citer ce compte rendu

Laflamme, D. (2002). Compte rendu de [Légaré, Jocelyne (dir.), Jamais de la vie. Écrits et images sur les pertes et les deuils, Montréal, Les éditions du passage, 2001, 190 p.] Frontières, 14(2), 95-95. https://doi.org/10.7202/1073983ar d'utilisation que vous pouvez consulter en ligne.

https://apropos.erudit.org/fr/usagers/politique-dutilisation/ 


\section{Légaré, Jocelyne (dir.) (2001)}

Jamais de la vie

Écrits et images

sur les pertes et

les deuils

Montréal, Les éditions du passage, 2001, 190 p.

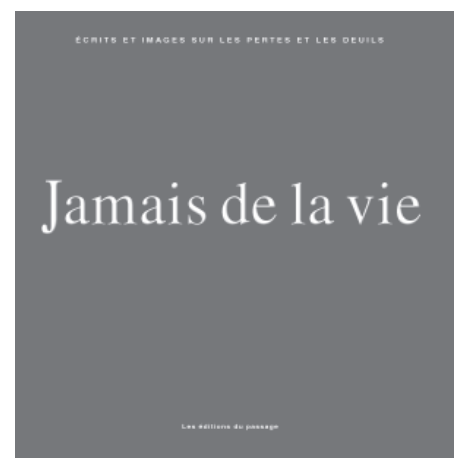

La mort n'est pas prononcée dans le titre de ce très beau livre, mais elle est bien là; très vite, elle occupe tout la place, sans compromis, à mesure que les dix-huit auteurs qui ont répondu à l'invitation de Jocelyne Légaré prennent la parole et que les images défilent sous nos doigts qui tournent les pages: papier glacé, moments d'éblouissement, de lumière qui brûle...

C'est un livre publié au Québec; on y trouve des mots d'ici et il évoque en même temps des ailleurs: des édifices, des paysages, des arbres... de la Floride, du Nicaragua, de SaintLouis du Sénégal, de Paris, Londres, Stockholm, Pretoria, Johannesburg, et même Carthage. Privés ou publics, ces lieux sont habités avec une grande intensité. Par ceux qui se préparent à partir, ceux qui sont partis, ceux qui sont restés. À tous les points de vue, ce parcours est une réussite: des textes d'une grande qualité littéraire accompagnés par une iconographie qui se fait présence, qui bouge à travers les pages couvertes de mots et qui nous aide à bouger entre les émotions qui se bousculent et qui nous bousculent à mesure que les voix s'amplifient pour dire que la mort est passée.

C'est un livre troublant, exigeant pour son lecteur. Un livre qui dit les choses sans fausse pudeur: ce qui fait vomir (p. 143, p. 111-116), les cinq cancers (p. 31-42), les " assauts précis et minutieux, discrets même, la mort à très légères doses " (p. 47), le courage et la volonté de celui qui "ferme ses systèmes» (p. 48), le fracas de l'eau qui entoure l'aveu: « Je n'ai rien fait» (p. 82). Ceux qui cherchent un message de consolation préféreront probablement s'abstenir. Pour écouter ces voix, il faut "accepter d'être démuni " (p. 16), comme l'écrit François Roustang dès le premier texte, intitulé « Deuil impossible ». Jamais plus de douze pages pour un même texte; parfois tout est dit en une page ou deux. C'est amplement suffisant; le mal est fait et nous restons avec "une fêlure dans le cœur" (Louise Mailhot, p. 21). Témoignages, dialogues avec celle ou celui qui est présent pour quelques précieux instants encore, ou qui n'est plus... ce sont des textes qui disent ouvertement que "ça ne passe pas", comme le constate Catherine Mavrikakis: "Tu y passes, ma fille. Mais quelque chose ne passe pas. Quelque chose ne passera jamais » (p. 111, 113).

Ce sont des textes où « les morts prennent de la place, même les petits morts "; pour Marie-Christine Lévesque, c'est le congélateur qu'il faut alors vider (p. 123) et, surpris, on la suit avidement dans cette surprenante cryothérapie. Par ailleurs, et bien sûr on s'en surprend moins, ce qui revient dans plusieurs des vingt récits, c'est une place vide qui se creuse d'elle-même dans une famille, dans un tissu familial ravagé. Arbitrairement, j'ai retenu ces phrases qui parlent au féminin et que je me hasarde ici à juxtaposer:

«Elle, dans sa famille, ils ne reconnaissent pas leurs morts. La raison en est simple : dans leur passé, toutes les morts de leurs morts ont été inutiles » (Suzanne Jacob, p. 53).

"Mon mari dit toujours: si je meurs, comme s'il avait le choix" (M.-C. Lévesque, p. 125).

«Ma mère est morte qui ne devait jamais mourir " (Anne Marie Alonzo, p. 141).

"Viens ma fille, nous appareillons ! » (Jocelyne Légaré, p.136).

Ce livre nous offre aussi des paroles de philosophes. Laurent-Michel Vacher propose une réflexion sur « le deuil de Dieu » (p. 71-77). II y a aussi ce marabout sénégalais qui se prête à une étrange interview dans un cimetière au sujet des morts, de ceux qui ont atteint, dit-il, la « sobriété " (p. 105):

"Pourquoi parlez-vous aux morts alors que vous avez dit qu'ils sont sourds?

Je ne suis pas un fou. Je ne parle pas aux morts. [...]
En regardant le monticule de terre devant lui, il dit: II me prend dans le silence du simple fait qu'il ne répond pas.

Je me tus. [...]

Il ajouta: Je parle à la mort. Je parle à celle qui sait. Je parle à celui qui, en moi, sait» (p.106).

Avec sa couverture d'un rouge somptueux, portant en relief les mots Jamais de la vie, ce livre est de la belle ouvrage! Les heures passées à fréquenter ces textes et ces images seront des heures graves, certes, car ce livre s'adresse à celle, à celui en nous qui sait.

Diane Laflamme 